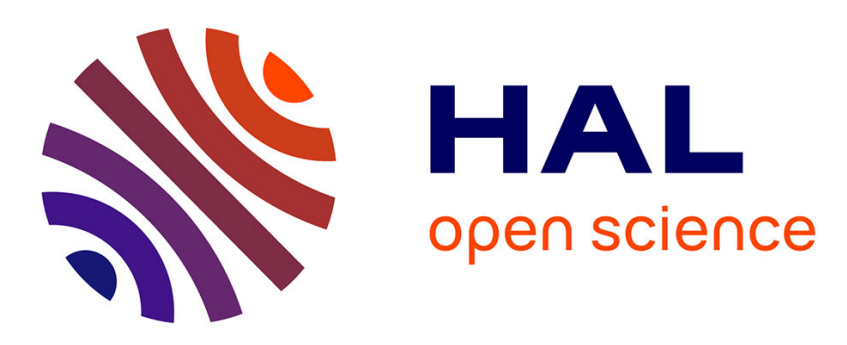

\title{
Optimization of the geopotential heights information used in a rainfall-based weather patterns classification over Austria
}

Pierre Brigode, Pietro Bernardara, Joël Gailhard, Federico Garavaglia, Pierre Ribstein, Ralf Merz

\section{To cite this version:}

Pierre Brigode, Pietro Bernardara, Joël Gailhard, Federico Garavaglia, Pierre Ribstein, et al.. Optimization of the geopotential heights information used in a rainfall-based weather patterns classification over Austria. International Journal of Climatology, 2012, pp.1097-0088. 10.1002/joc.3535 . hal-00719803

\section{HAL Id: hal-00719803 \\ https://hal.science/hal-00719803}

Submitted on 24 Jul 2012

HAL is a multi-disciplinary open access archive for the deposit and dissemination of scientific research documents, whether they are published or not. The documents may come from teaching and research institutions in France or abroad, or from public or private research centers.
L'archive ouverte pluridisciplinaire HAL, est destinée au dépôt et à la diffusion de documents scientifiques de niveau recherche, publiés ou non, émanant des établissements d'enseignement et de recherche français ou étrangers, des laboratoires publics ou privés. 


\section{Optimization of the geopotential heights information used in a rainfall based weather patterns classification over Austria.}

Pierre Brigode $^{1,2}$, Pietro Bernardara ${ }^{1,3}$, Joel Gailhard ${ }^{4}$, Federico Garavaglia ${ }^{4}$, Pierre Ribstein $^{2}$, Ralf Merz ${ }^{5}$

1 LNHE, EDF R\&D, Chatou, France.

2 UMR 7619 SISYPHE, UPMC, Paris, France

3 Saint-Venant Laboratory for Hydraulics, Chatou, France.

4 DTG,EDF, Grenoble, France

5 Department of Catchment Hydrology, UFZ Helmholtz Centre for Environmental Research, Halle, Germany

Corresponding author: Email: pierre.brigode@edf.fr

Key words: weather patterns, Austrian heavy rainfall, bottom-up classification, COST733, geopotential height field, optimization, comparison, daily precipitation shape fields. 


\section{Abstract}

Classifications of atmospheric circulation patterns are useful tools to improve the description of the climate of a given region and the analysis of meteorological situations. In particular, weather patterns (WP) classifications could be used to improve the description of spatial heavy rainfall. Here, a bottom up approach, previously used to build WP classification in France, is applied for the definition of a WP classification useful for the description of Austrian heavy rainfall. The optimal spatial extent and the optimal position of the geopotential fields to be taken into account for a WP classification is studied. The proposed WP classification is shown to be coherent with the general knowledge on synoptic situations responsible for heavy rainfall over Austria. Moreover, the classification has good performances in term of heavy rainfall spatial description compared to 152 COST 733 classifications defined in the same region. In particular, we show that the choice of spatial extent of the geopotential fields, their position and their characteristics is relevant for capturing physical information on synoptic situations responsible for heavy rainfall and that it can improve weather pattern classification performances. 


\section{Introduction}

The classification of atmospheric circulation and weather patterns is used in climate and meteorology researches since the beginning of these sciences, see El-Kadi and Smithson (1992), Yarnal et al. (2001), Huth et al. (2008) and Philipp et al. (2010) for reviews. The aim of these classifications is to define a limited number of typical synoptic meteorological situations for a given region. For instance, Kaufmann and Weber (1996) defined a classification over the Alpine region aiming at describing the typical Alps wind fields. In general, a circulation pattern classification is based only on geopotential fields; while a weather pattern (WP) classification is based on one or more geopotential fields and some other relevant meteorological variables. Here, we focus on weather pattern classification developed for heavy rainfall spatial explanation. This type of rainfall based weather pattern classification is able to provide information on heavy rainfall spatial distribution using geopotential information. Indeed, Littmann (2000) shows that geopotential fields can provide significant information on heavy rainfall events. Boé and Terray (2008) proposed a weather pattern classification to explain winter rainfall fields in France, while Romero et al. (1999), Trigo and DaCamara (2000) and Martínez et al. (2008) classifications were focused on rainfall description in Western Mediterranean region. Garavaglia et al. (2010) proposed a weather pattern classification on France for the estimation of heavy rainfall quantiles based on a compound distribution. These classification methodologies follow a "bottom-up approach": the "bottom" part consists of the definition of a given number of classes based on daily rainfall fields over a given region which are then linked to geopotential information in the "up" parts. Note that one of the main objective of these 
classifications is to be more focused on "where does it rain" information rather than on "how much does it rain" information. An important motivation for using this type of classification is that the bottom-up approach, consisting in linking the rainfall information to the geopotential fields, could a priori be very interesting for the exploration of future climate scenarios, giving the fact that global circulation models are known to give more robust information on large scale features like geopotential than on small spatial scale phenomena like rainfall (Räisänen 2007).

Traditionally, the geopotential height fields used in weather patterns classification are centered on the region for which the classification is done. Moreover, the spatial coverage of geopotential height fields is chosen depending on the available data and on the spatial extent of the region to be covered. However, the "optimal" classification could a priori be defined on a geopotential field not centered on the region. We argue that the spatial extent, the position and the characteristics of geopotential height fields used to classify weather patterns on a given region are important choices when defining a classification.

The general aim of the paper is thus to introduce a weather pattern classification useful for the description of Austrian heavy rainfall spatial distribution. The classification is based on a bottom up approach. The classification process is improved via the definition of an optimization procedure for the choice of the geopotential information considered. A specific aim of the paper is thus to show that the optimization procedure is relevant for capturing physical information on synoptic situations responsible for heavy rainfall and that it can improve weather pattern classification performances.

The optimization is based on the weather pattern classification methodology introduced by Garavaglia et al. (2010) for France, including methodological choices that are 
inherited of previous works on quantitative precipitation forecasting, using the analogue method (Guilbaud and Obled 1998, Obled et al. 2002 and Bontron 2004). Note that the geopotential grid used in the analogue method results from tests of different locations, sizes and characteristics (Obled et al. 2002). This methodology was shown to be useful for the definition of a rainfall compound distribution in France (Garavaglia et al. 2010) and was also applied to other domains (e.g. by Brigode et al. (2012) over British Columbia). All methodological hypotheses are listed and verified in the present study. The proposed optimization procedure consists in finding the size, the location and the characteristics of the geopotential fields that better explain the spatial distribution of the rainfall on a given region. The definition of a weather pattern classification over Austria is then presented. Several classifications were developed in the past for modeling rainfall over this region (Ehrendorfer 1987, Matulla et al. 2003, Seibert et al. 2006).

Recently, numerous weather pattern classifications have been defined over the region within the COST 733 action (Harmonisation and Applications of Weather Types Classifications for European Regions, http://cost733.met.no/about_cost733.htm). The COST 733 action main objective is to "achieve a general numerical method for assessing, comparing and classifying weather situations in Europe, scalable to any European (sub)region with time scales between $12 \mathrm{~h}$ and 3 days and spatial scales of 200 to $2000 \mathrm{~km}$, applicable for a number of applications". The performances of the proposed classification are thus compared to the performances of COST 733 classifications.

The method used for the weather pattern classification is summarized in section 2 . The rainfall and geopotential data used in the study are described in section 3 , while in section 4 the results of the optimization for the definition of Austrian weather patterns are presented and discussed. Finally, some conclusions are drawn in section 5. 


\section{Methodology}

As introduced in the previous section, a rainfall days classification is first generated as the "bottom" steps. This classification is then linked to different geopotential informations implementing the "up" steps.

\subsection{THE BOTTOM PART OF THE CLASSIFICATION: GENERATING ONE RAINFALL} CLASSIFICATION

This first part of the classification process is the "bottom" part, only dealing with rainfall information. The main objective of this part is to identify a limited number of typical rainfall classes characterized by similar heavy rainfall spatial patterns.

The first step consists of the selection of a "rainy days" sub-population. Suppose that a meteorological dataset is available and is composed of $n$ rainfall series observed on a given region at daily resolution. Each day $j$ is thus characterized by a rainfall vector of size $n$. The rainy days can be selected using an average rain depth threshold (for example, all the days with more than $5 \mathrm{~mm}$ of spatial average precipitation are considered as rainy days) or using a fixed proportion of all the observed days (for example, the $20 \%$ days with the highest rain depth are then considered as rainy days). The need of a classification more focused on "where does it rain" information than on "how much does it rain" information is fulfilled by the use of the "shapes" of the rainfall fields. These rainy day shapes, named $R_{j}$, are defined in a rainy days space of dimension $n$ and obtained with the normalization of each rainy day rainfall field by each day average precipitation depth.

In a second step, a Hierarchical Ascendant Classification (HAC) is performed on the $R_{j}$ vectors previously identified. The classes are generated using the Ward method (1963), 
which chooses iteratively the grouping presenting the minimum intra-class inertia (Cheng and Wallace 1993). The final number of rainfall classes $\left(N_{R C}\right.$, which contains all the rainfall classes and one non-rainy class) is determined by looking at the intra-class inertia evolution as a function of the number of classes. Finally, the $N_{R C}$ rainfall classes gather days characterized by rainfall fields with similar spatial distribution.

\subsection{THE FIRST "UP" STEPS: OPTIMIZATION OF THE GEOPOTENTIAL INFORMATION} USED

The "up" steps consist now in moving into the geopotential height space and finding optimal geopotential information explaining the rainfall generating processes coming from the synoptic scale.

First, the rainfall classes and the non-rainy class centroids are projected onto the geopotential height space. Like for the rainfall fields, geopotential field shapes are used and are thus previously estimated with the normalization of each geopotential field by each day average geopotential height. Each day $j$ is thus characterized by a geopotential field vector $G_{j}{ }^{m}$, where $m$ indicates the dimension of the geopotential field space. The centroid of the rainfall class $A$ is defined as the mean geopotential field vector of the $n_{A}$ days composing the class, named $G_{A}{ }^{m}$ in the defined geopotential space.

[1] $G_{A}^{m}=\frac{\sum_{j=1}^{n_{A}}\left(G_{j}^{m}\right)}{n_{A}}$

The geopotential height space can be composed of different geopotential fields at different heights (e.g. $500 \mathrm{hPa}, 700 \mathrm{hPa}, 1000 \mathrm{hPa}$, etc.) and recorded at different times (e.g. $0 \mathrm{~h}, 12 \mathrm{~h}, 24 \mathrm{~h}$, etc.) on several geographic locations (i.e. different grid points). For example, the geopotential height space of day $j$ can be described by a vector $G_{j}{ }^{1000}$, composed of 2 different height fields estimated on 500 grid points. The geopotential 
space used by Garavaglia et al. (2010) is characterized by a vector $\mathrm{G}^{440}$, because the geopotential space is defined at 2 heights $(700 \mathrm{hPa}$ and $1000 \mathrm{hPa})$, for 2 times per day ( $0 \mathrm{~h}$ and $24 \mathrm{~h}$ ) and on 110 points grid covering a spatial extent of around $10^{6} \mathrm{~km}^{2}$. Note that a Principal Component Analysis (PCA) of each potential space is implemented in order to reduce the number of dimensions of this space to 10. All the optimization procedure tends to find the optimal geopotential field space $m$ onto which the rainfall class centroids are projected.

\subsection{THE FINAL "UP" STEPS: RE-ATTRIBUTION OF EACH DAY TO ONE WEATHER} PATTERN

The last classification step consists in re-attributing each day (considered as rainy or not) to a given weather pattern in estimating the Euclidian distances between the considered day and the class centroids. The considered day is then attributed to the weather pattern witch is the closest one. Note that some "no-rainy days" can thus be considered as members of a rainy weather pattern if they are closer of a rainy weather pattern centroid in the considered geopotential space.

Finally, our classification is no more driven by the prior rainfall information but by the geopotential field information. Finding rainfall data set with good spatial and temporal coverage and good data quality over a specific area is harder than geopotential information. Thus, classifications can be easily extended using only other geopotential data set, like NOAA $20^{\text {th }}$ Century Reanalysis (6-hourly geopotential height fields from 1871 to 2011, Compo et al. 2011) or EMULATE reanalyses (daily mean sea-level pressure reconstructions over Europe for the period 1850-2003, Ansell et al. 2006). 


\subsection{CRAMÉR-VON-Mises test FOR CLASSIFICATION EVALUATION}

Numerous criteria exist for evaluating classification performance. The Cramér-von Mises test (Anderson 1962), named Cramér further, is typically used as a "basic" tool to check the discriminating power of a weather pattern classification in terms of rain/no rain occurrence (Bárdossy et al. 1995, Stehlik and Bárdossy 2003, Bliefernicht and Bárdossy 2007, Garavaglia et al. 2010). The Cramér coefficient can be estimated for each available rainfall series with a contingency table, constructed with the considered weather pattern classification (vector with one weather pattern for each day) and a vector of rain/no rain occurrence (vector with, for each day, either 0 if the rain average is null or 1 if rainfall is observed). Thus, the Cramér performances of each classification and each rainfall series are estimated as follows:

[2] Cramér $=\sqrt{\frac{\chi^{2}}{n_{d}}}$

where $\chi^{2}$ is the result of a classical dependence $\chi^{2}$ test between the weather pattern classification and the rain/no rain occurrence vector and $n_{d}$ is the number of classified days. This score ranges between 0 (no dependence between the classification and the observed rain/no rain occurrence) and 1 (absolute dependence). To focus on heavy precipitation, the Cramér coefficient can be estimated on a sub-sample population of heavy rainfall composed of the days with a precipitation amount greater than a given threshold. The performances of each weather pattern classification produced are thus evaluated using this type of score qualifying their discriminating power in terms of rain/no rain occurrence. Figure 1 presents an example of the evaluation of one hypothetical classification in three classes with the Cramér test. The considered classification is thus compared with a rain/no-rain vector generated from the observed 
rainfall record studied. A threshold $T$ can then be fixed in order to test the discriminating power of the classification in terms of heavy rainfall.

FIGURE 1. Example of Cramér performances (a) and of Cramér performances focused on heavy rainfall (over threshold $\mathrm{T}$ ) (b) obtained by three classes: classes 1 and 2 regroups rainfall days coming from two different situations and class 3 regroups the non-rainy days.

(a)

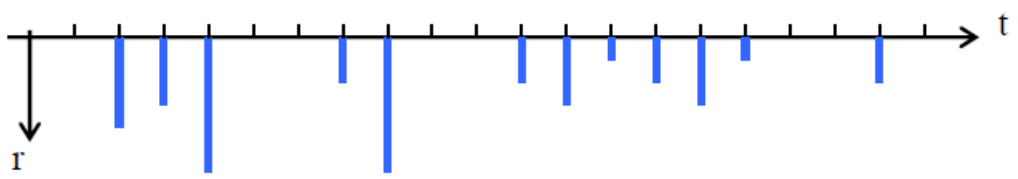

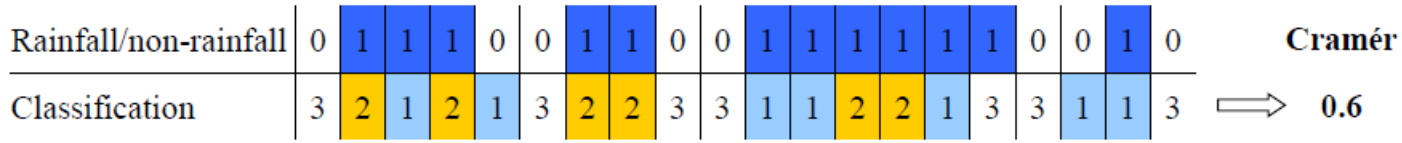

(b)

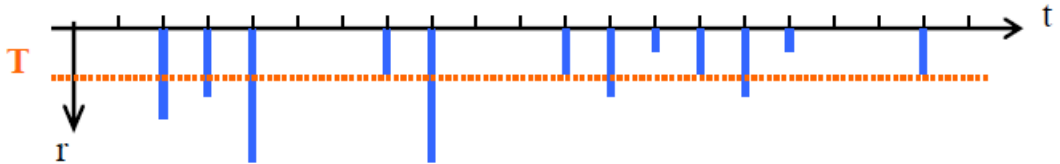

\begin{tabular}{|c|c|c|c|c|c|c|c|c|c|c|c|c|c|c|c|c|c|c|c|}
\hline 1-rainfall & 0 & | & 1 & & & & & 0 & 0 & & & & 0 & 0 & 0 & 0 & 0 & 0 & Cran \\
\hline & & ? & 1 & 2 & & & & 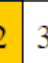 & 3 & & 1 & 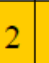 & 2 & 3 & 3 & 1 & 1 & & $\Longrightarrow 0.3$ \\
\hline
\end{tabular}




\section{Data}

The two archives used in this study are (i) information on rainfall fields (needed for the identification of Austrian rainfall classes) and (ii) information on the synoptic scale (required for the projection of these classes onto the geopotential height space). Weather pattern classifications defined in the COST action 733 are finally used for analyzing weather pattern classification performances.

\subsection{RAINFALL FIELDS}

The Austrian daily rainfall field is obtained from the European Climate Assessment and Data (ECA\&D) re-analyses data set (Haylock et al. 2008) providing daily precipitation amounts (calculated as the sum of rainfall at $18 \mathrm{UT}$ of the current day and rainfall at 06 UT of the next day) with a resolution of $0.5^{\circ} \times 0.5^{\circ}$ for the period 1950 to 2008 . A subdomain of $300000 \mathrm{~km}^{2}$ is extracted to cover the Austrian territory (from $9.25^{\circ} \mathrm{E}$ to $17.25^{\circ} \mathrm{E}$, and from $46.25^{\circ} \mathrm{N}$ to $49.25^{\circ} \mathrm{N}$ ) and consists thus of 119 rainfall re-analysis series. This grid is shown with red points in Figure 2.

\subsection{GeOPotential FIELDS}

The geopotential height space is characterized by daily geopotential height fields at 700 and $1000 \mathrm{hPa}$. These fields, provided by the National Center for Environmental Prediction (NCEP) and National Center for Atmospheric Research (NCAR) reanalysis (Kalnay et al. 1996), are defined on a $2.5^{\circ}$ resolution grid for 247 points in Western Europe, at $00 \mathrm{UT}$ and at $24 \mathrm{UT}$. Thus, each day is described by four geopotential fields defined on 247 points. The NCEP-NCAR grid is shown with black points in Figure 2. 
FIGURE 2. Map of the available data of geopotential height (NCEP-NCAR reanalysis, plotted with black points) and of rainfall data (ECA\&D reanalysis, plotted with red points) used in the present study.

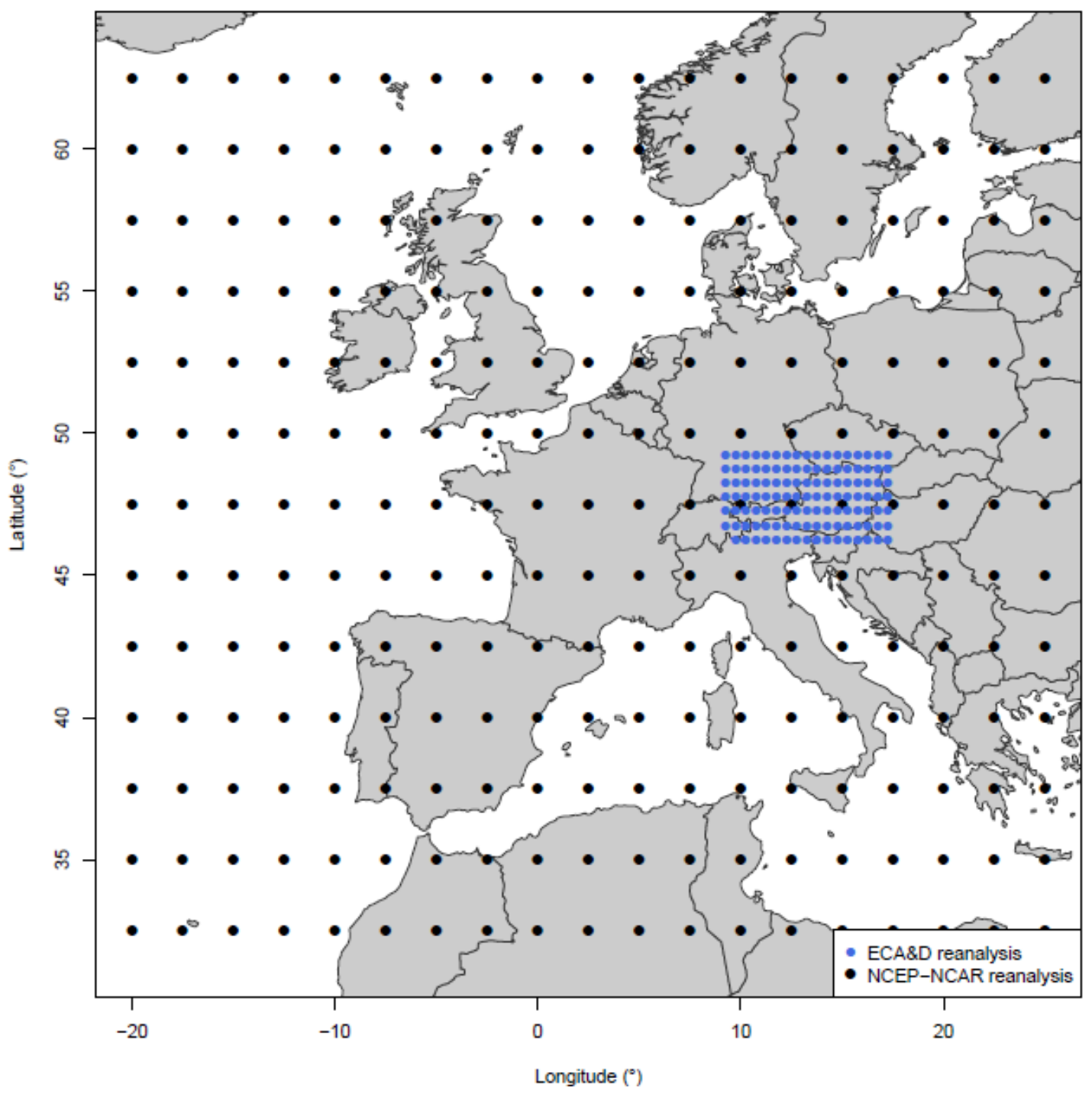

\subsection{COST733 WEATHER PATTERN CLASSIFICATIONS}

Numerous weather pattern classifications have been defined within COST 733 action and are available and could be downloaded on the COST 733 wiki website (http://geo23.geo.uni-augsburg.de/cost733wiki/). 76 COST 733 classifications defined 
two at a time on the domains D06 (Alps, $3^{\circ}$ to $20^{\circ} \mathrm{E}$ and $41^{\circ}$ to $52^{\circ} \mathrm{N}$ ) and D07 (Central Europe, $3^{\circ}$ to $26^{\circ} \mathrm{E}$ and $43^{\circ}$ to $58^{\circ} \mathrm{N}$ ) have been extracted in order to compare these classifications and the Austrian weather pattern classification defined here with a "bottom-up" approach. Note that these classifications have been defined with different methodologies and are characterized by different number of weather patterns (from 7 to 13 classes for the D06 domain and from 8 to 13 for the D07 domain). 


\section{Results}

4.1 The "Bottom" steps: Hierarchical Ascendant Classification of the RAINY DAYS

In this section, some first illustrations of the "bottom" steps, which results in the definition of one Austrian rainfall classification, are presented. Following the steps depicted in the section 2 , we defined a rainy day as a day with a total rainfall amount greater than the $80^{\text {th }}$ percentile of the total population.

The number of rainfall classes, and consequently the number of weather patterns, is here chosen by looking at the intra-class inertia evolution in the dendrogram as a function of the number of classes (Figure 3). Each difference $D_{1}$ is estimated as the absolute value of the difference between the intra-class inertia estimated for $n+1$ rainfall classes and the inertia estimated for $n$ classes. The intra-class inertia evolution suggests the choice of 4 rainfall classes and 1 non-rainy class. Note that, to ensure a significant number of observations in each class and define a simple operational classification, we should consider a parsimonious number of classes (typically fewer than 10 classes). For instance, in the "French classification" described in Garavaglia et al. (2010), this number is thereby fixed to 8 classes ( 7 rainy classes and 1 non-rainy class). Moreover, the previous works on Austrian rainfall classification result in a number of classes never higher than 7 (Matulla et al. 2003, Seibert et al. 2006). 
FIGURE 3. Dendrogram obtained from HAC of Austrian rainy days. (b) Intra-class inertia evolution. (c) 1-order differences of intra-class inertia evolution. The red boxes highlight the 4 rainfall classes identified, red points highlight the intra-class inertia of these 4 rainfall classes.
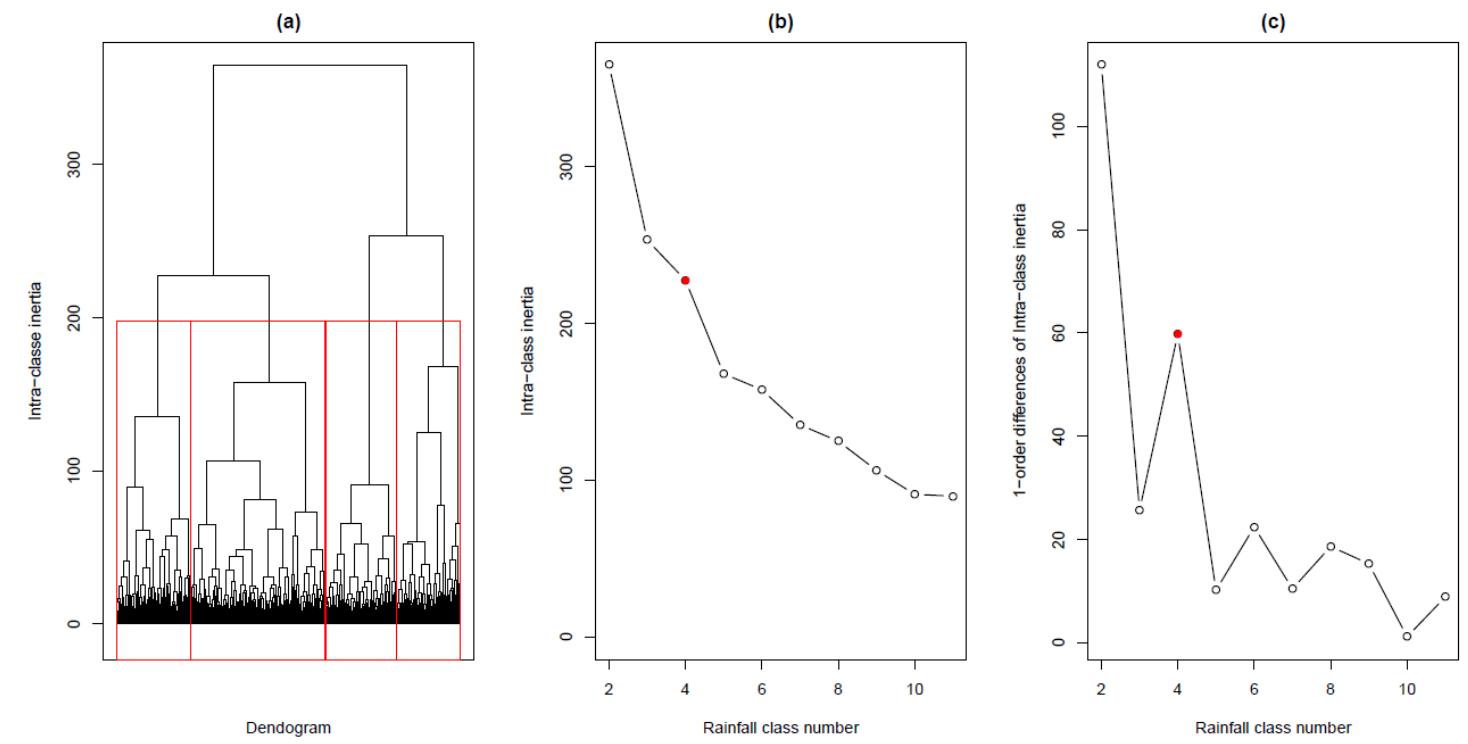

The choice of 5 classes ( 4 rainy classes and 1 non-rainy class) is also comforted by the visual analysis of the rainfall fields characterizing the 5 classes and reported in Figure 4. Indeed, we can observe that class 1 is characterized by a rainfall spatial distribution centred in the North Western part of Austria, in the North Eastern for class 2, in the South -East for class 3, in the South West for class 4; the class 5 is the non-rainy class. 
FIGURE 4. Ratio between the mean precipitation amount of each Austrian rainfall classes and the general mean precipitation amount (considering all rainfall classes)
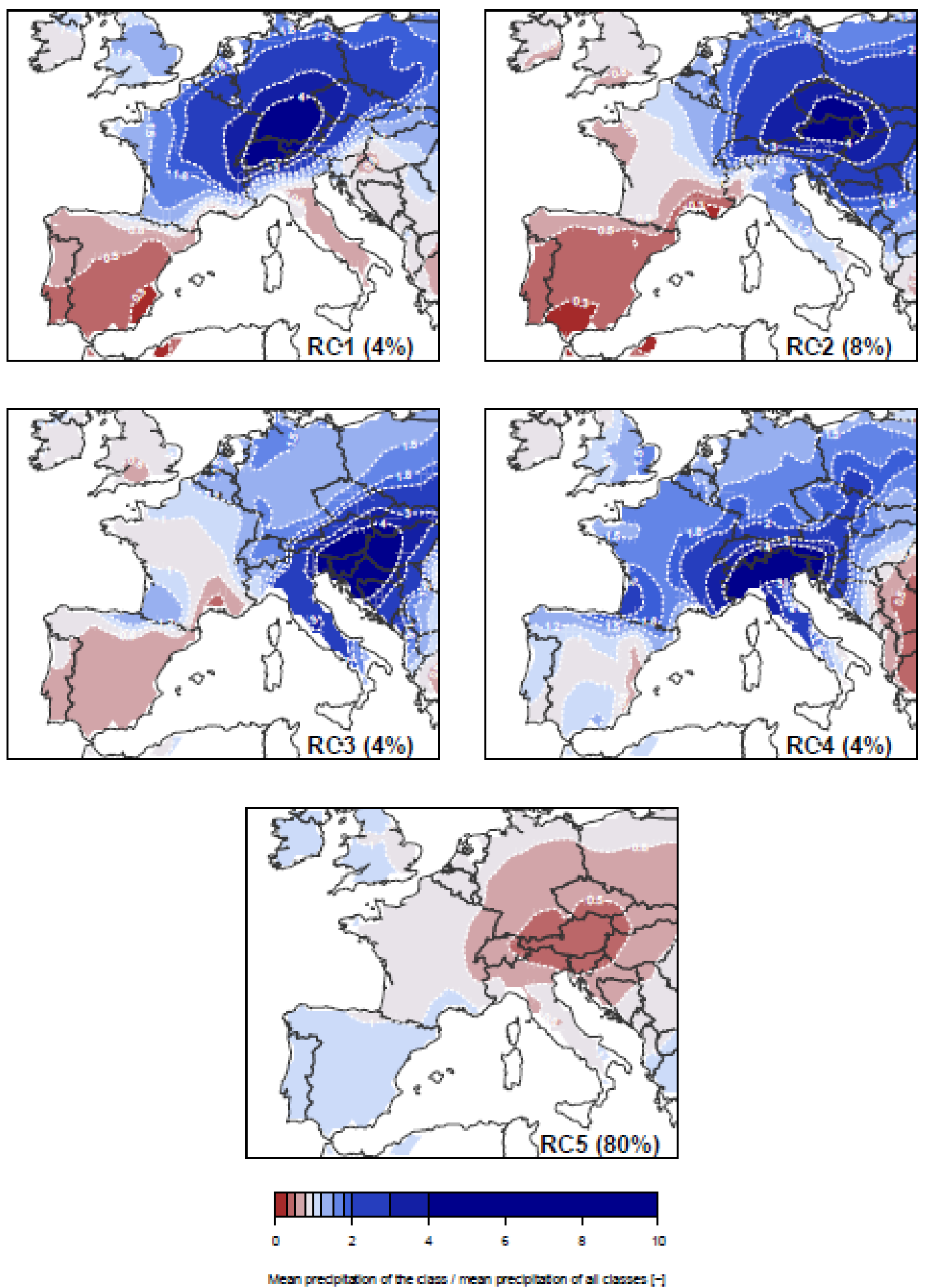


\subsection{ON THE "UP" PART OPTIMIZATION (GEOPOTENTIAL FIELDS POSITION AND SPATIAL EXTENT)}

In this section, we search the optimal geopotential space in terms of classification general performances. Following Garavaglia et al. (2010), we first defined the geopotential space as constituted by 4 geopotential height fields for each day: the 700 $\mathrm{hPa}$ and $1000 \mathrm{hPa}$ fields at $0 \mathrm{~h}$ and at $24 \mathrm{~h}$. Three different sizes of geopotential height grid are chosen. The first one is of size $3.0 \times 10^{6} \mathrm{~km}^{2}$ as used for the French weather patterns classification and further named "Size 1" (S1). A second size of approximately $0.6 \times 10^{6} \mathrm{~km}^{2}$ is chosen to entirely cover the Austrian territory, named "Size 2" (S2). The last one is of size around $0.9 \times 10^{6} \mathrm{~km}^{2}$, named "Size 3", (S3), which is a compromise between S1 and S2. 403 different classifications of weather types are generated, by moving the location of the centre of grids characterised by these three different spatial extents over Europe. Considering the spatial extent of the data set used in this study, the $\mathrm{S} 1$ center grid can thus be positioned in 88 locations, $\mathrm{S} 2$ in 165 and $\mathrm{S} 3$ in 150 . The 5 rainfall classes are projected onto each different geopotential space of dimension 216 (54 geopotential measure points x 2 heights x 2 measure hours), 60 (15 geopotential measure points $\times 2$ heights $\times 2$ measure hours), and 80 (20 geopotential measure points x 2 heights x 2 measure hours), respectively, resulting in different weather pattern classifications. The performances of each weather pattern classification are evaluated by the Cramér test estimated over the whole rainy days population (named Cramér ${ }_{0}$ hereafter) and over the heavy rainfall sub-sample exceeding a threshold, as depicted in section 2. This threshold $T$ is chosen here as $20 \mathrm{~mm}$. This choice is coherent with the previous results of Seibert et al. (2006) who used the mean precipitation $98^{\text {th }}$ percentile of 7 rainfall regions in Austria as a criterion for selecting "heavy precipitation days" and 
found a threshold around $20 \mathrm{~mm} / \mathrm{d}$. This "heavy Cramér" coefficient is further named "Cramér ${ }_{20}$ coefficient". Figure 5 presents the Cramér ${ }_{0}$ and the Cramér ${ }_{20}$ coefficients for each grid of geopotential heights (from S1 to S3 from top to bottom) and for each position of the grid. Thus, each colored point represents the barycentre of one grid and the colors correspond to the mean Cramér performances obtained on all the Austrian rainfall reanalyzes considered (blue points). Finally, the black box represents for each grid size and for each coefficient the location of the best geopotential height spatial extent. 
FIGURE 5. Cramér ${ }_{0}$ (left column) and Cramér ${ }_{20}$ (right column) coefficients for different positions of the geopotential height field barycentre used in weather pattern definition, for three spatial extents of the fields (from top to bottom S1 to S3). The spatial extent of the optimal position is reported on each map with a black box
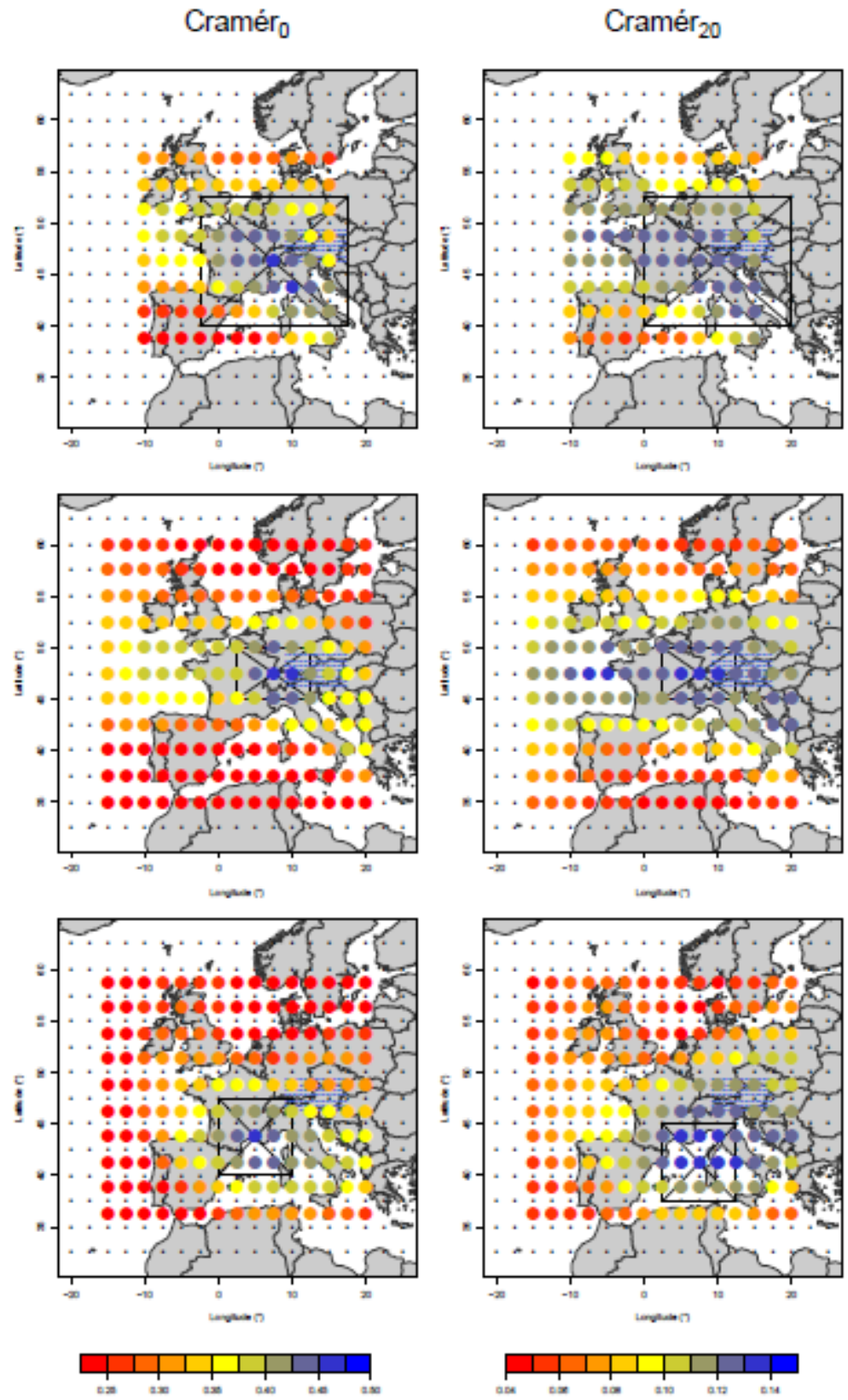
First, note that the geopotential grids centered on Austria are not the best grids in terms of Cramér ${ }_{0}$ and Cramér 20 , for all three sizes. The best performances are obtained for grids located in the South and in the West of Austria. Then, the West-East flux appears to have a major role in the Austrian rainfall processes. Thus, the more the geopotential grid centre moves away latitudinally from Austria the poorer the performances are in terms of rain/no-rain occurrence. On the contrary, a geopotential grid with very distant longitudinal locations offers some reasonable performances in terms of rain/no rain occurrence. For the S1 size for example, a classification based on a geopotential grid distant approximately from only $200 \mathrm{~km}$ North of Vienna (centered near Dresden) offers a Cramér ${ }_{0}$ coefficient lower than 0.30 whereas an other classification based on a grid distant from more than $4000 \mathrm{~km}$ (centered off the Bretagne coast and thus 20 times more distant than the precedent one), is characterized by a Cramér ${ }_{0}$ coefficient greater than 0.40. This tendency is more clearly observable for the S2 grid, with a clear latitudinal threshold of both Cramér coefficients: grid center locations over $55^{\circ} \mathrm{N}$ and under $37.5^{\circ} \mathrm{N}$ lead to weather pattern classifications with poor performances in terms of Austria rain/no rain occurrence. These results are coherent with those of previous studies focusing on Austrian heavy precipitations. Ehrendorfer (1987) stated that an important part of heavy rainfall events in Austria is due to West and South-West circulations. Moreover, Matulla et al. (2003) showed that the back trajectories for heavy precipitation days in Austria are coming mostly from West and South-West, like the dramatic Elba flood in 2002. It is important to note that Eastern or Northern circulations can equally generate heavy rainfalls. Nevertheless, the best quantity of heavy rainfall information in Austria is obtained when looking at the South-West geopotential height fields. 
The Cramér ${ }_{0}$ and Cramér 20 performance differences between the optimal grids of each size are non significant (greater than 0.45 for the Cramér $_{0}$ and greater than 0.14 for the Cramér 20 ) and we do not use these scores for the choice of the optimal grid. In order to cover a larger area and maximizing the potential geopotential information of our classification, we choose as optimal one a 1 grid (around $3 \times 10^{6} \mathrm{~km}^{2}$ ). The optimal grid is approximately centered on the Western Alps and thus not centering on the Austrian region (first line and first column black box of Figure 5).

\subsection{WHICH GEOPOTENTIAL INFORMATION TO BE USED IN OUR WEATHER-PATTERN CLASSIFICATION?}

In this section, we analyze the influence of the choice of the geopotential information used in our "up" steps on the classification performances. Note that we fixed in the precedent optimization procedure the geopotential space as constituted by 4 geopotential height shape fields for each day: the $700 \mathrm{hPa}$ and $1000 \mathrm{hPa}$ fields at $0 \mathrm{~h}$ and at 24h, following Garavaglia et al. (2010) methodology. We used now one grid size (S3 size) and we projected for each location the 5 rainfall classes onto geopotential spaces with different characteristics: using the shapes or the absolute values of the fields, using fields at $700 \mathrm{hPa}, 1000 \mathrm{hPa}$ or both, and using geopotential fields at $0 \mathrm{~h}$, or $0 \mathrm{~h}$ and $24 \mathrm{~h}$.

Figure 6 presents the Cramér $_{0}$ (first column) and Cramér $_{20}$ (second column) performances obtained for the 150 locations of S3 grid, using 5 different geopotential spaces for the 5 rainfall class projections. 
FIGURE 6. Cramer0 (a) and Cramer20 (b) performances obtained for 88 S1 grids by projecting the 5 rainfall classes onto different geopotential spaces: (A) absolute values of 700 and $1000 \mathrm{hPa}$ geopotential height fields at $0 \mathrm{~h}$ and 24h, (B) $1000 \mathrm{hPa}$ geopotential height shapes fields at $0 \mathrm{~h}$ and $24 \mathrm{~h},(\mathrm{C}) 700 \mathrm{hPa}$ geopotential height shapes fields at $0 \mathrm{~h}$ and 24h, (D) 700 and $1000 \mathrm{hPa}$ geopotential height shapes fields at $0 \mathrm{~h}$ and (E) 700 and $1000 \mathrm{hPa}$ geopotential height shapes fields at $0 \mathrm{~h}$ and $24 \mathrm{~h}$. The boxplots are constructed with the percentiles $0.10,0.25,0.50,0.75$ and 0.90
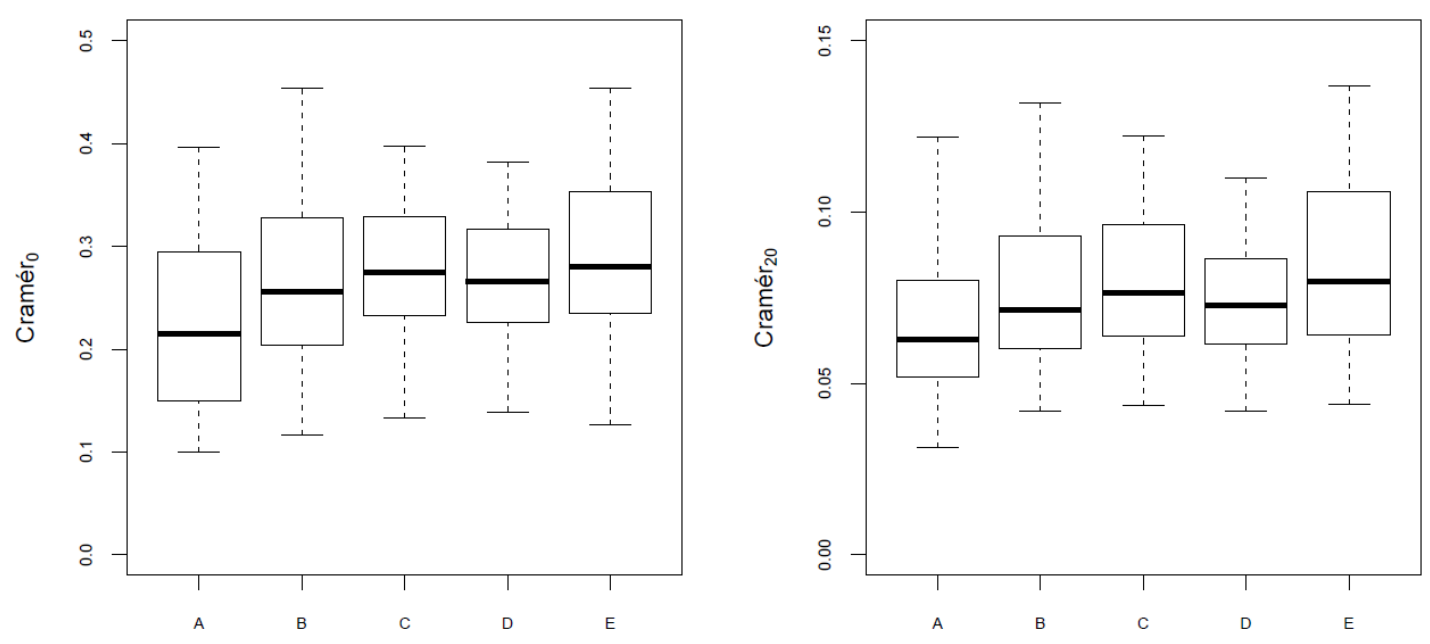

The first main result is that the two Cramér coefficients present the same "evolution tendencies". Thus, Cramér ${ }_{0}$ and Cramér 20 performances are clearly higher when shapes of geopotential height fields are considered (boxplots E) than when absolute geopotential fields are used (boxplots A). Similarly, using geopotential height fields at 700 and at $1000 \mathrm{hPa}$ (boxplots E) add significant rainfall information compared to using geopotential height fields at 700 (boxplots C) or at $1000 \mathrm{hPa}$ (boxplots B). Finally, the classifications considering a geopotential height data couple ( $0 \mathrm{~h}$ and $24 \mathrm{~h}$, boxplots E) perform better than those considering a single geopotential height field for each day ( $0 \mathrm{~h}$, 
boxplots D). These results are coherent with the findings of Obled et al. (2002) and Bontron (2004) in a precipitation forecasting context and validate the general applicability of the methodology used in Garavaglia et al. (2010).

\subsection{FINAL AUSTRIAN WEATHER PATTERN CLASSIFICATION ILLUSTRATION}

In this section, we illustrate the final Austrian weather pattern classification defined with the "optimal geopotential space": 4 geopotential shape fields (700 and $1000 \mathrm{hPa}$ at Oh and 24h) defined on an area of $3 \times 10^{6} \mathrm{~km}^{2}$ centred on the Western Alps.

Figure 7 presents the mean geopotential heights $(1000 \mathrm{hPa}$ at $0 \mathrm{~h})$ and ratio between the mean precipitation amount and the general precipitation amount (considering all WP) for each of the 5 Austrian weather patterns. 
FIGURE 7. Mean geopotential heights (1000 $\mathrm{hPa}$ at $0 \mathrm{~h})$ and Ratio between the mean precipitation amount of each Austrian weather pattern and the general mean precipitation amount(considering all weather patterns) for each of the 5 Austrian weather patterns. The black boxes represent the "optimal" geopotentiel space used for the "up" part of the classification

WP1 $(10 \%)$

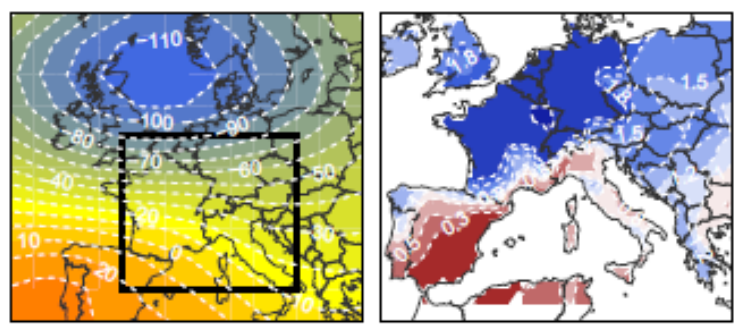

WP3 $(4 \%)$
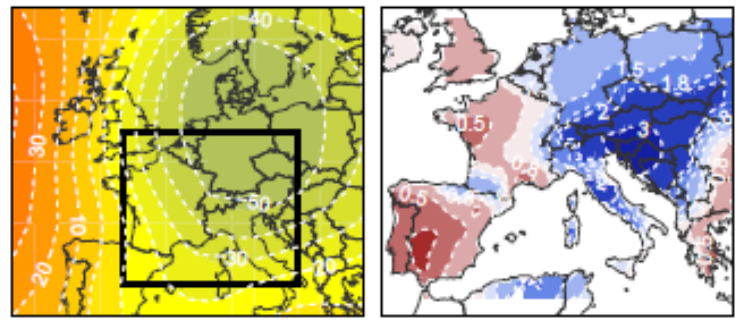

WP2 (15\%)

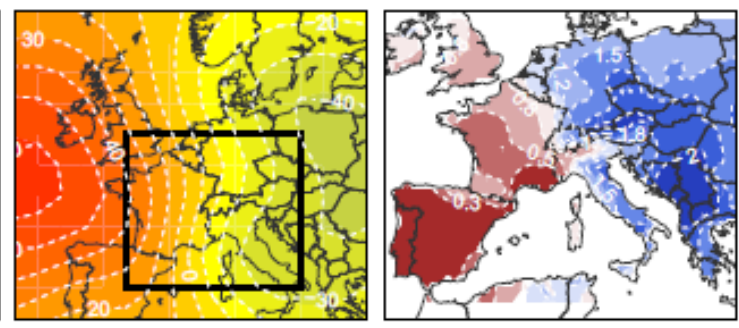

WP4 (19\%)

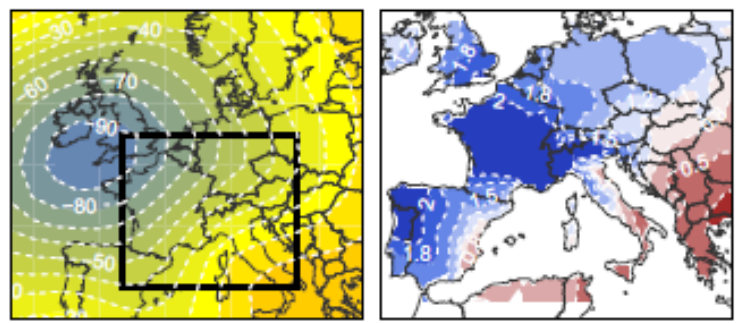

$(52 \%)$
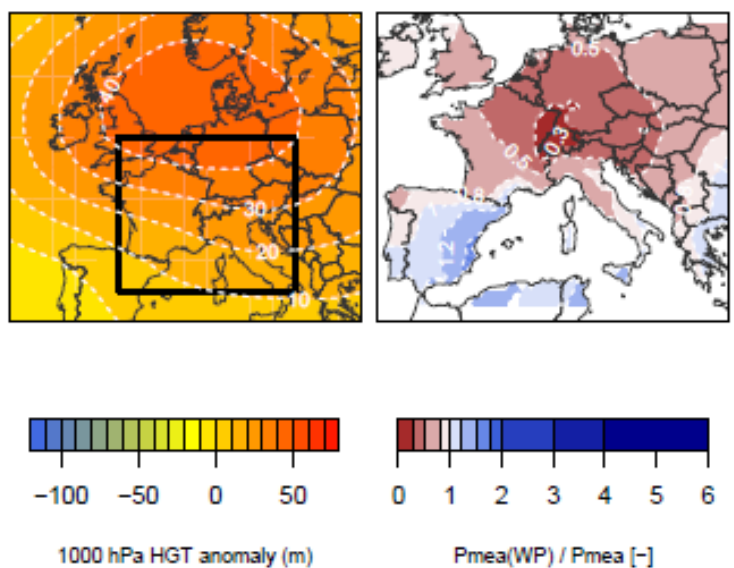

Pmea(WP) / Pmea [-]

The general patterns observed on the Austrian territory with the 5 rainfall classes are also identified at a larger scale with the 5 weather patterns, characterized by rainfall spatial distribution centred in the North Western part of Western Europe for WP1, in the 
Eastern for WP2, in the South Eastern for WP3, in the South Western for WP4 and the WP5 is the anticyclonic weather pattern. Logically, the spatial distribution of each weather pattern is no more concentred on the Austrian area, due to the Austrian rainfall classes projection into a larger geopotential space. Moreover, rainfall classes were identified on a rainy days sub-sample while weather patterns are constructed attributing each day to a weather pattern, anticyclonic or not. Thus, weather patterns can contained days with no rain observed on Austria and rainy days on the Northern part of Austria can have the same type of atmospheric circulation that a rainy day in the central part of Germany.

The evolution of each 5 clusters occurrence frequency, from the 5 original rainfall classes to the 5 final weather patterns, is presented in the Table 1.

TABLE 1. Evolution of the classes occurrence percentages from the five original rainfall classes to the five final WPs.

Rainfall classes

Weather patterns

\begin{tabular}{lcc}
\hline Class 1 & $5 \%$ & $9 \%$
\end{tabular}

Class 2

$7 \%$

$15 \%$

Class 3

$4 \%$

$4 \%$

Class 4

$4 \%$

$18 \%$

Class 5 (non-rainy)

$80 \%$

$54 \%$

Note that the number of days attributed to the anticyclonic weather pattern (WP5) is lower than the number of days of the "non-rainy" class (RC5), meaning that several Austrian non-rainy days are classified into the different non-anticyclonic weather 
patterns. At the same time, the frequencies of occurrence of each weather pattern are higher. This tendency has a limited impact on the desired discriminating power of our classification: the rainy days characterized by heavy rainfall in a particular area are always regrouped in the same class.

The Austrian weather patterns classification has been checked on a particular region in the North of Austria, the Kamp catchment at Zwettl in Niederösterreich. This catchment was particulary studied after the August 2002 extraordinary floods which happened in this region (Komma et al. 2007, Merz and Blöschl 2008). The spatial rainfall record observed on this catchment (from 1976 to 2006) contains significant heavy rainy days, like events in August 2002 which lead to major floods of the Kamp river. Thus, we have tested the classification on this rainfall record and provided interesting results (not shown here): the major rainfall records (containing August 2002 and other summer events: $52 \mathrm{~mm}$ the $06 / 08 / 1985,115 \mathrm{~mm}$ the $07 / 08 / 2002,81 \mathrm{~mm}$ the $12 / 08 / 2002$, etc.) are regrouped in one particular weather pattern, the WP2. Moreover, observed synoptic situations of these particular events showed similarities with the mean synoptic situation of the WP2, characterized by a continental depression. The Austrian weather pattern classification can thus provide interesting perspectives for heavy rainfall estimation on this particular catchment as for other ones.

Our final Austrian weather pattern classification is based on rainfall classes identified on Austrian rainy days but is at the end only driven by a geopotential height fields information at a larger scale. This classification can be daily updated by using geopotential height reanalyse dataset. 


\subsection{PERFORMANCES OF WEATHER PATTERN CLASSIFICATIONS}

The performances of the proposed weather pattern classification (named further "Austrian bottom-up classification") is compared in terms of Cramér 20 score on the Austrian daily rainfall re-analyses used in this study, to the performances of 76 COST 733 classifications. Each of the 76 COST classifications are defined on two spatial domains: D06 (Alps, $3^{\circ}$ to $20^{\circ} \mathrm{E}$ and $41^{\circ}$ to $52^{\circ} \mathrm{N}$ ) and D07 (Central Europe, $3^{\circ}$ to $26^{\circ}$ $\mathrm{E}$ and $43^{\circ}$ to $58^{\circ} \mathrm{N}$ ). Figure 8 presents (a) the spatial extent of the Austrian bottom-up classification domain (red color) and the two COST 733 classifications domains (black color for the D06 and blue color for the D07) and (b) Cramér 20 score for each of the 157 classifications (76 COST 733 classifications * 2 spatial domains +1 Final Austrian bottom-up classification +4 bottom-up classifications with different geopotential information used in the "up" steps of the classification). 
FIGURE 8. (a) Spatial extents of the two COST 733 domains (D06 in black and D07 in blue) and of the optimal geopotential heights information used for defining Austrian bottom-up classification (red). (b) Cramér20 performances obtained by the 152 COST 733 classifications (76 D06 classifications in black and 76 D07 classifications in blue) by the Austrian bottom-up classification (red) and by using different geopotential height information for defining Austrian weather patterns (orange lines).
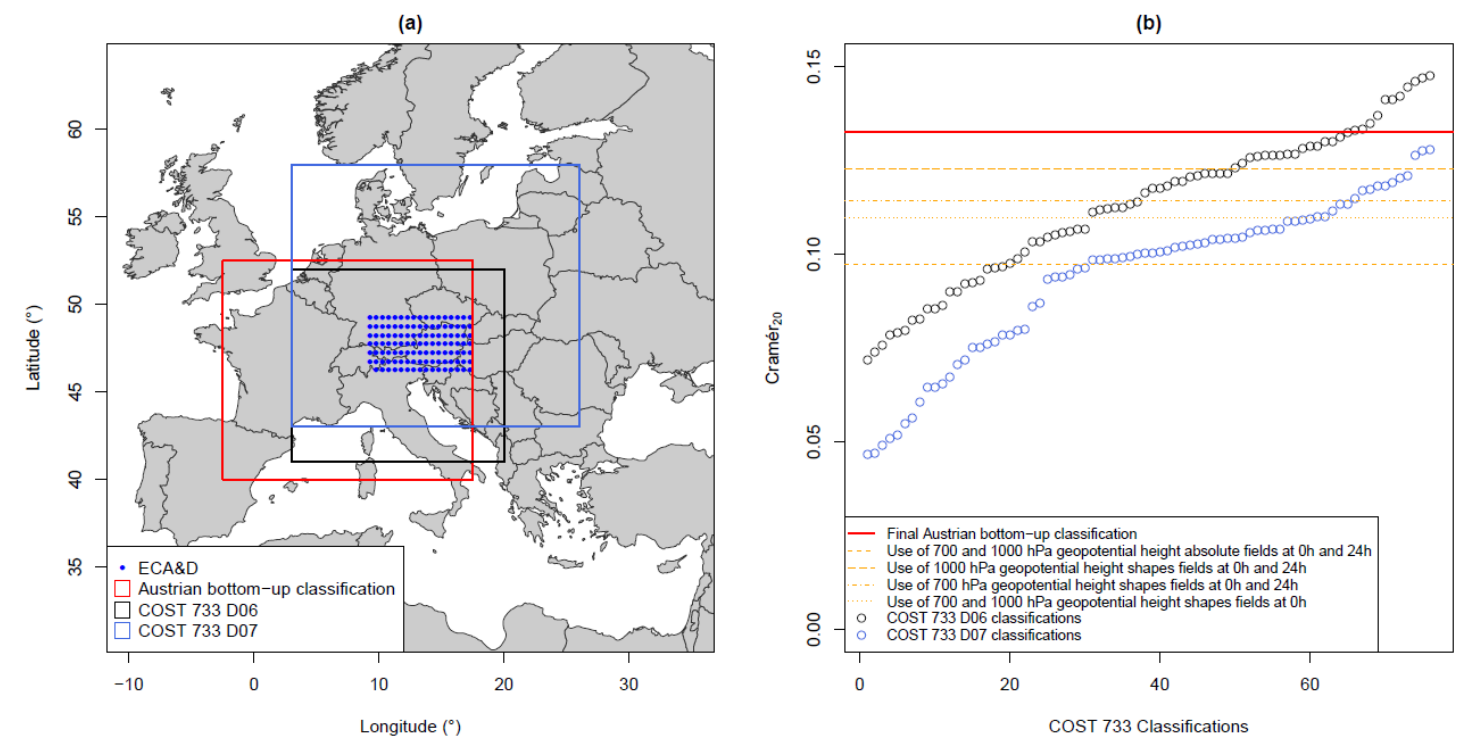

For each classification, the Cramér 20 score plotted in Figure 8 (b) is estimated as the average Cramér 20 score estimated on the 119 Austrian ECA\&D re-analyses points. Performances of the Austrian bottom-up classification are similar to the best performing COST 733 D06 (Alps) classifications in terms of Cramér 20 and are better than all the COST 733 D07 (Central Europe) classifications. Finally, the final Austrian bottom-up classification performs better than the bottom-up classifications using less geopotential information, showing that considering geopotential height fields shapes at both 700 and $1000 \mathrm{hPa}$ and at $\mathrm{Oh}$ and $24 \mathrm{~h}$ improves significantly the classification performances. 


\section{Conclusions}

In this paper, a parsimonious (only 5 classes) and discriminating (contrasted classes in terms of rainfall and geopotential fields) Austrian weather pattern classification, useful for spatial heavy rainfall description is proposed. The 5 classes are originated from rainfall information but the final classification is only driven by a geopotential height fields information (grid of around $3 \times 10^{6} \mathrm{~km}^{2}$, centred on the Western Alps). Updating the classification is then easy to perform by using long geopotential height reanalyse dataset or future geopotential height fields from General Circulation Models, which are more robust data sources than punctual (in time and space) rainfall record informations. This type of classification can lead to different applications, as extreme flood estimation on a particular catchment (using weather pattern classification as a sub-sample tool for the characterization of the rainfall risk, SCHADEX (Paquet et al. 2006) approach) or characterization of future climatic evolution (using weather pattern classification as an evaluation tool of the future climate model predictions). Moreover, we investigated the optimal spatial extent, the position and the characteristics of the geopotential fields to be taken into account for a rainfall based weather pattern classification. We show that the choice of the spatial extent and the position of the centre of the geopotential heights is an important issue. It is possible that the optimal geopotential field is not centred on the studied region and potentially do not exactly cover the studied region. The performances of the weather pattern classification using optimized geopotential height spatial extent and size are shown to be good in comparison with COST 733 weather pattern classifications where the geopotential height field is fixed a priori as two different domains. Moreover, the location of the optimal geopotential fields can be 
explained from the physical and climatic phenomena leading to heavy rainfall. In addition to the identification of the "optimal" weather pattern classification, this approach allows the general comprehension of the synoptic processes involved in the precipitation over the studied region. 


\section{Acknowledgment}

We acknowledge the E-OBS dataset from the EU-FP6 project ENSEMBLES (http://ensembles-eu.metoffice.com) and the data providers in the ECA\&D project (http://eca.knmi.nl). The NCEP-NCAR reanalysis data were provided by the NOAACIRES Climate Diagnostics Center, Boulder, Colorado, USA, from their Web site at http://www.cdc.noaa.gov/. 


\section{Reference list}

Anderson, T.W., 1962. On the Distribution of the Two-Sample Cramer-von Mises Criterion. Ann. Math. Statist. 33, 1148-1159.

Ansell, T.J., Jones, P.D., Allan, R.J., Lister, D., Parker, D.E., Brunet, M., Moberg, A., Jacobeit, J., Brohan, P., Rayner, N.A., Aguilar, E., Alexandersson, H., Barriendos, M., Brandsma, T., Cox, N.J., Della-Marta, P.M., Drebs, A., Founda, D., Gerstengarbe, F., Hickey, K., Jónsson, T., Luterbacher, J., Nordli, Ø, Oesterle, H., Petrakis, M., Philipp, A., Rodwell, M.J., Saladie, O., Sigro, J., Slonosky, V., Srnec, L., Swail, V., GarcíaSuárez, A.M., Tuomenvirta, H., Wang, X., Wanner, H., Werner, P., Wheeler, D., Xoplaki, E., 2006. Daily Mean Sea Level Pressure Reconstructions for the EuropeanNorth Atlantic Region for the Period 1850-2003. J. Climate 19, 2717-2742.

Brigode, P., Micovic Z., Bernardara P., Gailhard J., Paquet E., Garavaglia F., and Ribstein P. 2012. Link Between Rainfall-based Weather Patterns Classification over BritishColumbia and El Niño Southern Oscillations. EGU General Assembly 2012, 14:8029. Vienna: Geophysical Research Abstracts.

Bárdossy, A., Duckstein, L., Bogardi, I., 1995. Fuzzy rule-based classification of atmospheric circulation patterns. International Journal of Climatology 15, 1087-1097.

Bliefernicht, J., Bárdossy, A., 2007. Probabilistic forecast of daily areal precipitation focusing on extreme events. Natural Hazards and Earth System Sciences 7, 263-269.

Boé, J., Terray, L., 2008. A Weather-Type Approach to Analyzing Winter Precipitation in France: Twentieth-Century Trends and the Role of Anthropogenic Forcing. J. Climate 21, 3118-3133.

Bontron, G., 2004. Prévision quantitative des précipitations: adaptation probabiliste par recherche d'analogues. Utilisation des ré-analyses NCEP/NCAR et application aux précipitations du Sud-Est de la France. PhD Thesis, Polytechnic Institute of Grenoble, pp 286, Grenoble, 2004.

Cheng, X., Wallace, J.M., 1993. Cluster Analysis of the Northern Hemisphere Wintertime 500-hPa Height Field: Spatial Patterns. Journal of Atmospheric Sciences 50, 2674 2696.

Compo, G. P, J. S Whitaker, P. D Sardeshmukh, N. Matsui, R. J Allan, X. Yin, B. E Gleason, et al. 2011. "The Twentieth Century Reanalysis Project." Quarterly Journal of the Royal Meteorological Society 137 (654) (January 1): 1-28. doi:10.1002/qj.776.

Ehrendorfer, M., 1987. A regionalization of Austria's precipitation climate using principal component analysis. International Journal of Climatology 7, 71-89.

El-Kadi, A.K.A., Smithson, P.A., 1992. Atmospheric classifications and synoptic climatology. Progress in physical geography 16, 432-455.

Garavaglia, F., Gailhard, J., Paquet, E., Lang, M., Garçon, R., Bernardara, P., 2010. Introducing a rainfall compound distribution model based on weather patterns subsampling. Hydrol. Earth Syst. Sci. 14, 951-964.

Guilbaud, S., Obled, C., 1998. Daily quantitative precipitation forecast by an analogue technique: optimisation of the analogy criterion. Comptes Rendus de l'Académie des Sciences - Series IIA - Earth and Planetary Science 327, 181-188.

Haylock, M.R., Hofstra, N., Tank, A.M.G.K., Klok, E.J., Jones, P.D., New, M., 2008. A European daily high-resolution gridded data set of surface temperature and precipitation for 1950-2006. Journal of Geophysical Research 113, D20119.

Huth, R., Beck, C., Philipp, A., Demuzere, M., Ustrnul, Z., Cahynová, M., Kyselý, J., Tveito, O.E., 2008. Classifications of Atmospheric Circulation Patterns. Annals of the New York Academy of Sciences 1146, 105-152. 
Kalnay, E.C., Kanamitsu, M., Kistler, R., Collins, W., Deaven, D., Gandin, L., Iredell, M., Saha, S., White, G., Woollen, J., others, 1996. The NCEP/NCAR 40-year reanalysis project. Bulletin of the American Meteorological Society 77, 437-471.

Kaufmann, P., Weber, R.O., 1996. Classification of mesoscale wind fields in the MISTRAL field experiment. Journal of Applied Meteorology 35, 1963-1979.

Komma, J., Reszler, C., Blöschl, G., Haiden, T., 2007. Ensemble prediction of floods catchment non-linearity and forecast probabilities. Natural Hazards and Earth System Sciences 7, 431-444.

Littmann, T., 2000. An empirical classification of weather types in the Mediterranean Basin and their interrelation with rainfall. Theoretical and Applied Climatology 66, 161171.

Martínez, C., Campins, J., Jansà, A., Genovés, A., 2008. Heavy rain events in the Western Mediterranean: an atmospheric pattern classification. Advances in Science and Research 2, 61-64.

Matulla, C., Penlap, E.K., Haas, P., Formayer, H., 2003. Comparative analysis of spatial and seasonal variability: Austrian precipitation during the 20th century. Int. J. Climatol. 23, 1577-1588.

Merz, R., Blöschl, G., 2008. Flood frequency hydrology: 2. Combining data evidence. Water Resources Research 44, W08433.

Obled, C., Bontron, G., Garçon, R., 2002. Quantitative precipitation forecasts: a statistical adaptation of model outputs through an analogues sorting approach. Atmospheric research 63, 303-324.

Paquet, E., Gailhard, J., Garçon, R., 2006. Evolution of the GRADEX method : improvement by atmospheric circulation classification and hydrological modelling. La Houille Blanche 80-90.

Philipp, A., Bartholy, J., Beck, C., Erpicum, M., Esteban, P., Fettweis, X., Huth, R., James, P., Jourdain, S., Kreienkamp, F., 2010. COST733CAT-a database of weather and circulation type classifications. Physics and Chemistry of the Earth, Parts A/B/C 35, $360-373$.

Räisänen, J., 2007. How reliable are climate models? Tellus A 59, 2-29.

Romero, R., Sumner, G., Ramis, C., Genovés, A., 1999. A classification of the atmospheric circulation patterns producing significant daily rainfall in the Spanish Mediterranean area. International Journal of Climatology 19, 765-785.

Seibert, P., Frank, A., Formayer, H., 2006. Synoptic and regional patterns of heavy precipitation in Austria. Theor. Appl. Climatol. 87, 139-153.

Stehlik, J., Bárdossy, A., 2003. Statistical comparison of European circulation patterns and development of a continental scale classification. Theoretical and Applied Climatology 76, 31-46.

Trigo, R.M., DaCamara, C.C., 2000. Circulation weather types and their influence on the precipitation regime in Portugal. International Journal of Climatology 20, 1559-1581.

Ward, J.H., 1963. Hierarchical grouping to optimize an objective function. Journal of the American Statistical Association 58, 236-244.

Yarnal, B., Comrie, A.C., Frakes, B., Brown, D.P., 2001. Developments and prospects in synoptic climatology. International Journal of Climatology 21, 1923-1950. 